\title{
Ion-Selective Nanosensor for Photoacoustic and Fluorescence Imaging of Potassium
}

\author{
Chang H. Lee ${ }^{\dagger}$, Jeff Folz ${ }^{\ddagger}$, Wuliang Zhang ${ }^{\dagger}$, Janggun Jo§, Joel W. Y. Tan§, Xueding \\ Wang ${ }^{*},, \|$, and Raoul Kopelman ${ }^{*}, \dagger, \neq, \S$ \\ †Department of Chemistry, University of Michigan, Ann Arbor, Michigan 48109, United States \\ ‡Biophysics Program, University of Michigan, Ann Arbor, Michigan 48109, United States \\ $\S$ Department of Biomedical Engineering, University of Michigan, Ann Arbor, Michigan 48109, \\ United States \\ "Department of Radiology, University of Michigan, Ann Arbor, Michigan 48109, United States
}

\section{Abstract}

Ion-selective optodes (ISOs), the optical analog of ion-selective electrodes, have played an increasingly important role in chemical and biochemical analysis. Here we extend this technique to ion-selective photoacoustic optodes (ISPAOs) that serve at the same time as fluorescence-based ISOs, and apply it specifically to potassium $\left(\mathrm{K}^{+}\right)$. Notably, the potassium ion is one of the most abundant cations in biological systems, involved in numerous physiological and pathological processes. Furthermore, it has been recently reported that the presence of abnormal extracellular potassium concentrations in tumors suppresses the immune responses and thus suppresses immunotherapy. However, unfortunately, sensors capable of providing potassium images in vivo are still a future proposition. Here, we prepared an ion-selective potassium nanosensor (NS) aimed at in vivo photoacoustic (PA) chemical imaging of the extracellular environment, while being also capable of fluorescence based intracellular ion-selective imaging. This potassium nanosensor $\left(\mathrm{K}^{+}\right.$ NS) modulates its optical properties (absorbance and fluorescence) according to the potassium concentration. The $\mathrm{K}^{+} \mathrm{NS}$ is capable of measuring potassium, in the range of $1 \mathrm{mM}$ to $100 \mathrm{mM}$, with high sensitivity and selectivity, by ISPAO based measurements. Also, a near infrared dye surface modified $\mathrm{K}^{+} \mathrm{NS}$ allows fluorescence-based potassium sensing in the range of $20 \mathrm{mM}$ to 1 $\mathrm{M}$. The $\mathrm{K}^{+} \mathrm{NS}$ serves thus as both PA and fluorescence based nanosensor, with response across the

\footnotetext{
*Corresponding Authors: kopelman@umich.edu.; xdwang@umich.edu. Supporting Information

The Supporting Information is available free of charge on the ACS Publications website at DOI: 10.1021/acs.analchem.7b00930. Synthesis route for amine modified Pluronic F68; fluorescamine assay to confirm primary amine group availability; absorption spectra of $\mathrm{K}^{+} \mathrm{NS}$ in $0.01 \mathrm{M} \mathrm{HCl}$ and $0.01 \mathrm{M} \mathrm{NaOH}$; direct colorimetric comparison of the $\mathrm{K}^{+} \mathrm{NS}$ in different potassium concentrations; reversibility of the $\mathrm{K}^{+} \mathrm{NS}$; PA signals at different concentrations of potassium; PA calibration with PA intensity ratio vs potassium concentrations (linear scale); fluorescence calibration with protonation degree vs potassium concentrations (linear scale; PDF).

ORCID

Chang H. Lee: 0000-0002-4649-833X

Raoul Kopelman: 0000-0002-7770-8272

Notes

The authors declare no competing financial interest.
} 
biologically relevant $\mathrm{K}^{+}$concentrations, from the extracellular $5 \mathrm{mM}$ typical values (through PA imaging) to the intracellular $150 \mathrm{mM}$ typical values (through fluorescence imaging).

\section{Graphical abstract}

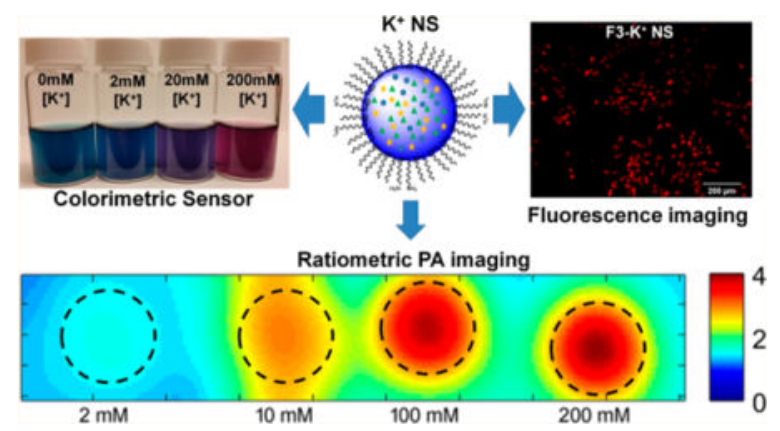

The analysis of complex ex vivo biological fluids, such as whole blood or urine, has been one of the most valuable diagnostic tools in clinical chemistry, where much use is made of ion-selective electrodes (ISEs). ${ }^{1}$ The more recent alternative to ISEs, the ion-selective optodes (ISOs), were originally ion-selective bulk optodes, a type of electrolyte sensor composed of lipophilic sensing components embedded in lipophilic materials that provided colorimetric detection of the sensed ions. ${ }^{1-4}$ A cation selective bulk optode senses the analyte cation through the competing equilibrium between $\mathrm{H}^{+}$and the analyte. ${ }^{1-4}$ As the analyte binds to the lipophillic ionophore in the sensing matrix, the $\mathrm{H}^{+}$from the lipophillic chromoionophore (a pH indicator dye), in that sensing matrix, is exchanged with the analyte cation, so as to maintain the equilibrium between the media inside and outside the optode. The ratio between protonated and unprotonated chromoionophore, derived from the optical spectra, correlates with the analyte concentrations at fixed $\mathrm{pH}$ values. To achieve equivalent information inside live cells, in vitro, the ISOs had to be miniaturized, that is, to the minute volumes covering optical fiber nanotips, ${ }^{5}$ or contained in nanoparticle-sensors (called NanoPEBBLEs). ${ }^{6-26}$ With such miniaturization, the traditional optical absorbance based detection is impractical, and thus, these ISOs had to be adapted to work in a fluorescence based mode, as nano-optodes, using fluorescence microscopy. Here we extend their capabilities, so as to also work as ISPAOs (ion-selective photoacoustic optodes).

As pointed out above, optical ion sensors (or optodes) can be utilized by either absorbanceor fluorescence-based spectroscopy, depending on the design of the sensors and their application. Information acquired through optical spectroscopy allows accurate chemical sensing at a given location. However, the performance of such optodes has to compete with that of the "gold standard" of ion-selective electrodes (ISEs) for in vivo or ex vivo studies. A key advantage of using optodes over ISEs is their potential to generate noninvasive chemical imaging, in vitro as well as in vivo. To generate chemical images using optically induced nanosensors, one of two imaging modalities (fluorescence imaging and photo-acoustic imaging) can be applied. Fluorescence imaging has already been applied to in vivo chemical, ion-selective imaging. ${ }^{27}$ However, as the imaging depth increases, not only does the signalto-noise ratio decrease drastically, but also the spatial resolution degrades, as a result of the overwhelming scattering of light in tissues. As an alternative technology, photoacoustic (PA) 
imaging overcomes the above limitations of fluorescence imaging, while still keeping the high sensitivity in imaging the optical contrast agents. ${ }^{27-32}$ The absorption of pulsed light by the molecules of the optical contrast agents is transferred into thermo-elastic expansion of tissue and then detected through ultrasound, with little scattering by tissues, thus significantly enhancing the spatial resolution when imaging objects beyond the sample's surface.

Here, a bimodal nanosensor (NS) has been prepared for $\mathrm{K}^{+}$as the target ion (called $\mathrm{K}^{+} \mathrm{NS}$ ), which can be applied for both fluorescence and PA imaging modalities, that is, as ISO or ISPAOs. The potassium ion, $\mathrm{K}^{+}$, is one of the major biological cations; it is involved in controlling numerous physiological processes, such as enzyme activation, maintaining $\mathrm{pH}$, regulation of blood pressure, as well as in nerve and muscle signal transmission. Just recently, Eil et al. reported that the typical elevation of extracellular $\mathrm{K}^{+}$concentration (5-10fold increase) in the tumor microenvironment led to the suppression of the activity of immune cells. ${ }^{33}$ Immunotherapy of tumors has been considered as one of the most promising avenues of cancer therapy, outdoing the traditional avenues of radiation therapy and chemotherapy. Thus, understanding the immune suppression mechanism due to abnormally high extracellular $\mathrm{K}^{+}$concentration (local hyperkalemia) created by the tumor is of high biological interest and may have a large impact on research as well as in the clinic.

This bimodal $\mathrm{K}^{+}$sensing nanosensor $\left(\mathrm{K}^{+} \mathrm{NS}\right)$ is prepared with primary amine groups on the nanoparticle's surface, which can be used for surface modification, such as cell-specific targeting for in vivo applications. ${ }^{34-36}$ Another potential usage of the primary amine groups is demonstrated by conjugating a near-infrared (NIR) absorbing/fluorescence reference dye, so as to achieve an NIR absorbing nanosensor, which is preferable for in vivo studies, in order to minimize tissue light scattering during optical imaging. The prepared $\mathrm{K}^{+} \mathrm{NS}$ shows an excellent response to biologically relevant $\mathrm{K}^{+}$concentration changes (from extracellular 5 $\mathrm{mM}$ to intracellular $150 \mathrm{mM}$ values) ${ }^{37}$ while remaining silent toward other biologically relevant cations in that concentration range. The $\mathrm{K}^{+}$NS's response to $\mathrm{K}^{+}$concentrations is demonstrated here by using UV-vis spectroscopy, fluorescence spectroscopy, and PA spectroscopy, as well as by PA imaging.

\section{EXPERIMENTAL SECTION}

\section{Materials}

All of the chemicals were purchased from Sigma-Aldrich unless otherwise noted.

\section{$\mathrm{K}^{+}$Nanosensor ( $\left.\mathrm{K}^{+} \mathrm{NS}\right)$ Preparation and Characterization}

Amine-modified Pluronic F68 was synthesized according to the previously reported methods. ${ }^{38}$ Pluronic F68 (75.6 mg), Pluronic P123 (116 mg, BASF), amine-modified Pluronic F68 (8.4 mg), dioctyl secabacate (DOS; $14 \mu \mathrm{L}$ ), chromoionphore I (1.5 mg, 2.57 $\mathrm{mmol}$ ), potassium ionophore III ( $5 \mathrm{mg}, 5.15 \mathrm{mmol})$, sodium tetrakis[3,5-bis(trifluoromethyl)phenyl]borate (NaTFPB; $9.75 \mathrm{mg}, 11 \mathrm{mmol}$ ), butyl methacrylate $(5 \mu \mathrm{L})$, and 1,6-hexanediol dimethacrylate ( $5 \mu \mathrm{L}$ ) were dissolved in $\sim 10 \mathrm{~mL}$ of dichloromethane

(DCM). Then, the solvent was evaporated via rotary evaporation and left in the hood, open, 
overnight. The thin film generated at the round-bottom flask was resuspended in Millipore water $(10 \mathrm{~mL})$. The suspended solution was flushed with Argon, while stirring, and $100 \mu \mathrm{L}$ of ammonium persulfate ( $10 \% \mathrm{w} / \mathrm{w}$ in water) and $100 \mu \mathrm{L}$ of $N, N, N^{\prime}, N^{\prime}-$

tetramethylethylenediamine were injected into the solution to initiate radical polymerization of butyl methacrylate and 1,6-hexanediol dimethacrylate. After $2 \mathrm{~h}$, the solution was purified by Amicon Ultra-15 Centrifugal Filter ( $100 \mathrm{kDa})$ with water $(5$ times) and Tris-HCl buffer $(10 \mathrm{mM}) \mathrm{pH} 7.4$ (5-10 times) until the sensing solution turns blue. The size of $\mathrm{K}^{+}$ Nanosonophore was measured by Dynamic Light Scattering (Beckman Coulter). Absorption spectra were obtained by a UV-vis spectrometer (Shimadzu UV-1601) and fluorescence spectra were obtained by a fluorimeter (Horiba FluoroMax-3). The primary amine group availability on the $\mathrm{K}^{+} \mathrm{NS}$ is confirmed by a fluorescamine assay (Figure S3). Fluorescamine is a nonfluorescence molecule which fluoresces upon reacting with primary amines. An analogous batch of $\mathrm{K}^{+}$NS was prepared with only Pluronic F68 instead of amine modified Pluronic F68. The fluorescence of fluorescamine in $\mathrm{K}^{+} \mathrm{NS}$ was several folds higher than the fluorescence of fluorescamine in $\mathrm{K}^{+} \mathrm{NS}$ without primary amine availability.

\section{Photoacoustic (PA) Spectroscopy Setup}

An optically clear polyvinyl chloride tube (I.D. $\times$ O.D. $=1 / 16$ in. $\times 1 / 8$ in.), containing solutions of the $\mathrm{K}^{+} \mathrm{NS}(\sim 5 \mathrm{mg} / \mathrm{mL})$, with various concentrations of $\mathrm{K}^{+}$, was placed in a water bath. An optical parametric oscillator (SLOPO Plus, Continuum), pumped with the second harmonic of a pulsed $(5 \mathrm{~ns})$ neodymium-doped aluminum garnet (Nd: YAG) laser (Surelite, Continuum), was used for excitation (at 540 and $660 \mathrm{~nm}$ wavelengths, respectively). The PA signal was detected by a $2.25 \mathrm{MHz}$ unfocused ultrasonic transducer (V323, Panametrics) connected to an amplifier (5072PR, Olympus). The signal, digitalized by an oscilloscope (TDS540, Tektronix), was collected (averaged over 200 pulses). The laser pulse was focused with a converging lens where the sample is located inside the tube. The raw PA signals are normalized with the power of the laser and PA signals from the empty tube. The signal intensity at $540 \mathrm{~nm}$ when divided by the signal intensity at $660 \mathrm{~nm}$ gave the ratio used for calibration. With ratios determined for each sample at each potassium concentration $(n=4)$, an average and a standard deviation were obtained.

\section{PA Imaging Setup}

Gelatin phantoms were prepared by dissolving gelatin (from porcine skin) in hot water ( 80 $\mathrm{g} / \mathrm{L}$ ) containing four 16 gauge needles. Then, the phantom cooled down to room temperature overnight. The 16 gauge needles were carefully removed and four different solutions of $\mathrm{K}^{+}$ NS $(\sim 5 \mathrm{mg} / \mathrm{mL})$ were carefully filled. As soon as the solutions were inserted, the PA images were acquired by an imaging system built on a commercially available research ultrasound platform (V1, Verasonics) with a linear array probe (CL15-7 with central frequency 11.25 $\mathrm{MHz}$, Philips) working at $10 \mathrm{~Hz}$. The laser pulse was diverged with a diverging lens so as to cover the entire imaging region $(1.5 \mathrm{~cm} \times 3 \mathrm{~cm})$. The phantom PA images $(540$ and $660 \mathrm{~nm})$ were averaged over 50 images and were smoothed by a Gaussian filter. The phantom PA image at $540 \mathrm{~nm}$ was divided by the phantom PA image at $660 \mathrm{~nm}$ so as to acquire the ratiometric potassium image. 


\section{Near Infrared Absorbing $\mathrm{K}^{+}$Nanosensor (NIR-K+ NS) Preparation}

To a stirring $10 \mathrm{~mL}$ of solution ( $15 \mathrm{mg}$ of the $\mathrm{K}^{+} \mathrm{NS}$ in PBS pH 7.4), $0.05 \mathrm{mg}$ of NIR-797 isothiocyanate ( $5 \mathrm{mg} / 100 \mu \mathrm{L}$ in DMSO) was added and stirred overnight. The solution was purified by an Amicon Ultra-15 Centrifugal Filter (100 kDa) with water $(5 \times)$ and Tris-HCl buffer $(10 \mathrm{mM}) \mathrm{pH} 7.4(5-10 \times)$. The prepared NIR-K ${ }^{+}$NS was analyzed by a UV-vis spectrometer and fluorimeter.

\section{F3-K+ NS Preparation}

To modify the surface of the $\mathrm{K}^{+}$NS, Bifunctional Polyethylene Glycol (MAL-PEG-SCM, 2 $\mathrm{kDa}$, Creative PEGWorks; $8 \mathrm{mg}$ ) was added into $\mathrm{K}^{+} \mathrm{NS}$ in PBS (pH 7.4; $50 \mathrm{mg} / 2.5 \mathrm{~mL}$ ). After 30 min of stirring, it was washed with PBS using an Amicon Ultra-15 Centrifugal Filter (100 kDa) and an F3 Peptide (KDEPQRRSARLSAKPAPPKPEPKP-KKAPAKKC, RS Synthesis; $22 \mathrm{mg}$ ) was added and stirred overnight. Cysteine (1.26 mg) was added and stirred for $2 \mathrm{~h}$ to deactivate unreacted maleimide groups. The nanosensor solution was washed with water $(5 x)$ then concentrated before usage. To confirm F3 conjugation onto the $\mathrm{K}^{+} \mathrm{NS}$, a separate batch was synthesized where the F3-peptide was preconjugated with NIR-797. The absorbance of NIR-797 was still visible after the purification.

\section{Fluorescence Imaging Setup}

HeLa cells (ATCC) were cultured in DMEM medium supplemented with 10\% Fetal Bovine Serum (FBS) and $1 \%$ antibiotic-antimycotic. Cells were incubated with $\mathrm{K}^{+} \mathrm{NS}$ (without

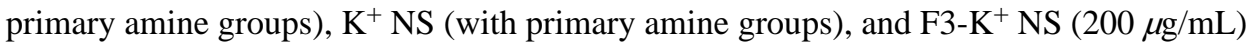
inside the growth medium for $30 \mathrm{~min}$. After incubation, the nanosensor containing media were removed and washed with fresh colorless DMEM media $(3 \times)$. Cell images were immediately taken on an Olympus IX71 microscope (10x objective) using a high resolution monochromatic camera (Retiga 6000, QImaging). Cells were illuminated using a broad excitation filter $(510-550 \mathrm{~nm})$ with a red $(630 \mathrm{~nm})$ emission filter; the filters were originally optimized and used without any modification for propidium iodide. Images were captured using the Micro-Manager software package: an extension of ImageJ.

\section{Degree of Protonation Calculations}

We note that calibrations in this field are performed as protonation degree, termed $\pi$ or (1$a$ ), versus concentration for both absorbance- and fluorescence-based measurements. The PA calibrations were generated by simply using the ratios of the two signal intensities. This degree of protonation $(\pi=1-a)$ was calculated as described previously. ${ }^{3,25}$ For the $\mathrm{K}^{+} \mathrm{NS}$, the degree of protonation, for a system using two sensing signals, follows the standards eq 1 .

$$
\pi=1-\alpha=1\left(1+S \frac{R-R_{\min }}{R_{\max }-R}\right)^{-1}
$$

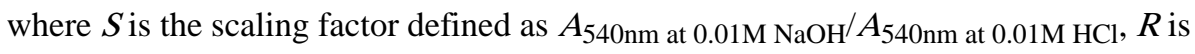
$A_{660 \mathrm{~nm}} / A_{540 \mathrm{~nm}}, R_{\min }$ is $A_{660 \mathrm{~nm} \text { at } 0.01 \mathrm{M} \mathrm{NaOH}} / A_{540 \mathrm{~nm} \text { at } 0.01 \mathrm{M} \mathrm{NaOH}}$, and $R_{\max }$ is $A_{660 \mathrm{~nm} \text { at } 0.01 \mathrm{M} \mathrm{HCl}} A_{540 \mathrm{~nm} \text { at } 0.01 \mathrm{M} \mathrm{HCl} \text {. }}$ 
For NIR-K ${ }^{+}$NS, the degree of protonation, for a system using one sensing signal and one reference signal, follows eq 2 .

$$
\pi=1-\alpha=\frac{R-R_{\max }}{R_{\max }-R_{\min }}
$$

where $R$ is $A_{660 \mathrm{~nm} / A 800 \mathrm{~nm}}\left(\right.$ or $\mathrm{Fl}_{660 \mathrm{~nm}} / \mathrm{Fl}_{820 \mathrm{~nm}}$ ), $R_{\max }$ is $A_{660 \mathrm{~nm} \text { at } 1 \mathrm{M} \mathrm{KCl}} / A_{800 \mathrm{~nm} \text { at } 1 \mathrm{M} \mathrm{KCl}}$

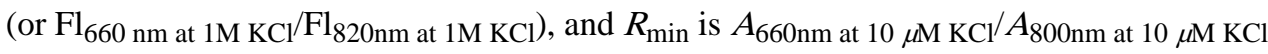
(or $\mathrm{Fl}_{660 \mathrm{~nm} \text { at } 10 \mu \mathrm{M} \mathrm{KCl}} / \mathrm{Fl}_{820 \mathrm{~nm} \text { at } 10 \mu \mathrm{M} \mathrm{KCl}}$ ). $\mathrm{Fl}_{660 \mathrm{~nm}}$ represents all fluorescence intensities from $\mathrm{Fl}_{620 \mathrm{~nm}}$ to $\mathrm{Fl}_{700 \mathrm{~nm}}$ and $\mathrm{Fl}_{820 \mathrm{~nm}}$ represents all fluorescence intensities from $\mathrm{Fl}_{800 \mathrm{~nm}}$ to $\mathrm{Fl}_{840 \mathrm{~nm}}$.

\section{RESULTS AND DISCUSSION}

\section{$\mathrm{K}^{+}$Sensing Nanosensor ( $\left.\mathrm{K}^{+} \mathrm{NS}\right)$ Preparation and Its Response to Different $\left[\mathrm{K}^{+}\right]$}

The $\mathrm{K}^{+}$NS was prepared via regular micelle formation using Pluronics (Figure 1a). Each of the self-assembled micelles contains all of the hydrophobic sensing components including acrylic monomers. The acrylic monomers in the core of the nanosized micelles were polymerized via free radical polymerization to form the $\mathrm{K}^{+} \mathrm{NS}$. Micelles are prone to fall apart below the critical micelle concentration. Thus, acrylic polymerization makes the core of the matrix more rigid, allowing the sensor to be more stable in biological settings. The $\mathrm{K}^{+}$ NS exhibited an average size of around $60 \mathrm{~nm}$ when measured by dynamic light scattering. The sensor shows direct colorimetric changes with differing potassium concentrations (Figure S5). The primary amine group availability on the $\mathrm{K}^{+} \mathrm{NS}$ is confirmed by fluorescamine assay (Figure S3). Fluorescamine reacts with primary amines becoming fluorescent. The fluorescence of fluorescamine in $\mathrm{K}^{+} \mathrm{NS}$ was around 2-fold higher than the fluorescence of fluorescamine in $\mathrm{K}^{+} \mathrm{NS}$ without primary amine availability. Figure $1 \mathrm{~b}$ shows absorption spectra of the $\mathrm{K}^{+} \mathrm{NS}$ at different $\mathrm{K}^{+}$concentrations. As the $\mathrm{K}^{+}$concentration increases, the chromoionophore inside the $\mathrm{K}^{+} \mathrm{NS}$ gets deprotonated $(540 \mathrm{~nm}$ peak increases and $660 \mathrm{~nm}$ peak decreases) and vice versa. The ratio between two sensing peaks (540 and $660 \mathrm{~nm}$ ) is used for calibration in the later studies.

\section{$\mathrm{K}^{+}$NS Calibration and Its Selectivity with Respect to Other Cations}

Both sensing peaks can be used to compute the calibration curve between protonation degree and $\log$ of $\left[\mathrm{K}^{+}\right]$. The protonation degree was calculated based on previously described methods using two sensing peaks. ${ }^{3}$ The sensing component ratios were experimentally found to give a maximum change from 1 to $100 \mathrm{mM}$ of $\mathrm{K}^{+}$concentrations (Figure 2). It was experimentally determined that the dynamic range of the sensor was influenced by the ratios between the sensing components. For example, a sensor made with low molar amounts of potassium ionophore III compared to chromoionophore I has optimal sensing range at lower potassium concentrations. The $\mathrm{K}^{+} \mathrm{NS}$ is capable of sensing outside of the range ( $1 \mu \mathrm{M}$ to 1 $\mathrm{M})$, but absorbance changes at the sensing peaks are not as drastic as the $1-100 \mathrm{mM}$ range. 
Although the potassium ionophores inside the optodes are designed to have strong binding affinities to certain ions, binding other ions that have similar sizes and properties cannot be completely avoided. The $\mathrm{K}^{+} \mathrm{NS}$ was tested for its selectivity compared to other biologically relevant cations (Figure $2 \mathrm{a}, \mathrm{Na}^{+}, \mathrm{Ca}^{2+}$, and $\mathrm{Mg}^{2+}$ ). The $\mathrm{K}^{+} \mathrm{NS}$ only starts to respond to $\mathrm{Na}^{+}$, $\mathrm{Ca}^{2+}$, and $\mathrm{Mg}^{2+}$ concentrations higher than $10 \mathrm{mM}$ while the sensor response in $100 \mu \mathrm{M}$ of $\mathrm{K}^{+}$. The sensor's selectivity of potassium over other cations is a few orders of magnitude higher. The responses of the $\mathrm{K}^{+} \mathrm{NS}$ from $\mathrm{Ca}^{2+}$ and $\mathrm{Mg}^{2+}$ are negligible since typical extracellular $\mathrm{Ca}^{2+}$ and $\mathrm{Mg}^{2+}$ concentrations are around 2.5 and $2 \mathrm{mM}$, respectively. ${ }^{39}$ On the other hand, $\mathrm{Na}^{+}$is one of the most abundant cations in biological systems along with $\mathrm{K}^{+}$and sodium's typical extracellular concentration is around $140 \mathrm{mM} .{ }^{37}$ In Figure $2 \mathrm{~b}$, the $\mathrm{K}^{+} \mathrm{NS}$ still possesses its sensing capability to potassium even with high background $\mathrm{Na}^{+}$ concentration $(150 \mathrm{mM})$. The background interference of sodium causes the calibration curve to shift a little bit, but similar trend has already been observed in ISOs and ISEs. ${ }^{1}$ Thus, satisfactory calibrations can be generated in the presence of other competing cations so as to measure $\mathrm{K}^{+}$in complex biological fluids. The sensor is fully reversible and can respond to local potassium changes within a few seconds (Figure S6).

\section{$\mathrm{K}^{+}$NS Calibration by Photoacoustic (PA) Spectroscopy}

The photoacoustic effect correlates with the absorbance characteristics of the optical contrast agent. ${ }^{29}$ Figure 3a shows two absorption spectra of the $\mathrm{K}^{+} \mathrm{NS}$ in two different potassium concentrations ( 2 and $200 \mathrm{mM}$ ). As described, the absorbance at $540 \mathrm{~nm}$ increases and absorbance at $660 \mathrm{~nm}$ peak decreases as potassium concentration increases. Figure 3b,c shows the exemplary PA signals of $\mathrm{K}^{+} \mathrm{NS}$ in phantoms at different potassium concentrations. As potassium concentration increases from 2 to $200 \mathrm{mM}$, the PA signal intensity increases when excited with $540 \mathrm{~nm}$ (Figure 3b). On the other hand, PA signal intensity decreases as the potassium increases when excited with $660 \mathrm{~nm}$ (Figure 3c). Examples of raw PA signals at other potassium concentrations are shown in Figure S7. The sensor's absorption properties can be also detected through PA spectroscopy. The ratio between the intensities of PA spectra at two excitations (540 and $660 \mathrm{~nm}$ ) gave the calibration curve (Figure 3d). Here, we directly plotted the ratio between two excitations to form the calibration curve. The PA ratio of the $540 \mathrm{~nm}$ over the $660 \mathrm{~nm}$ excitations shows a logarithmic relationship with the $\mathrm{K}^{+}$concentrations that we have tested $(1-200 \mathrm{mM})$ in phantoms. From the absorbance calibrations (Figure 2b), it is evident that the influence of the sodium background $(150 \mathrm{mM})$ cannot be neglected. The PA ratios derived from the 540 $\mathrm{nm}$ and the $660 \mathrm{~nm}$ excitations were generated in the presence of physiological sodium concentrations $(150 \mathrm{mM})$ and still formed logarithmic relationship with the potassium concentrations. Evidently, the sensitivity of the $\mathrm{K}^{+}$NS has been lowered due to the sodium interference. However, the typical extracellular potassium concentration is $\sim 5 \mathrm{mM}$, while the tumor extracellular potassium concentration has been reported to be $5-10$-fold higher. ${ }^{33}$ The $\mathrm{K}^{+} \mathrm{NS}$ can still differentiate between 4 and $20 \mathrm{mM}$, as shown in the calibration curve.

\section{$\mathrm{K}^{+}$NS Response to PA Imaging}

The PA images of the four different $\mathrm{K}^{+}$concentrations $(2,10,100$, and $200 \mathrm{mM})$ were taken simultaneously. Two images were taken with $540 \mathrm{~nm}$ (Figure 4a) excitation and $660 \mathrm{~nm}$ excitation (Figure $4 b$ ). Both Figure $4 a$ and $b$ do not show any specific trend at different 
potassium concentrations. Because a diverging lens was used to guide the laser pulse to the entire phantom, the power of the laser was not uniformly distributed among samples. The ratiometric PA image (Figure 4c) shows clear differences between 2, 10, and $100 \mathrm{mM}$ of potassium (Figure 4c). At concentrations of 100 and $200 \mathrm{mM}$, the ratiometric PA intensities from the image do not differ too much, indicating that the sensor has almost reached its saturation near $200 \mathrm{mM}$. The results suggest that the sensor is applicable in PA imaging.

\section{Utilization of Primary Amine Groups on K+ NS for Near-Infrared Absorption/Emission (NIR- $\left.\mathrm{K}^{+} \mathrm{NS}\right)$}

One of the unique features that the $\mathrm{K}^{+} \mathrm{NS}$ possesses is the molecular engineering availability using a primary amine. Primary amine groups can be utilized for surface modification to conjugate both targeting moieties and reference dyes. Targeting moieties allow the nanoparticle to actively home in on a certain type of cells, for example, cancer cells, giving the nanoparticle its cancer targetability in vivo. ${ }^{34,36}$ As for the PA imaging, the $\mathrm{K}^{+} \mathrm{NS}$ do not need a secondary reference dye because the chromoionophore already has two sensing peaks, the ratio of which can be used as an internal reference. However, the $\mathrm{K}^{+} \mathrm{NS}$ has only a single emission $(\sim 660 \mathrm{~nm})$. One solution to this issue is by conjugating onto the $\mathrm{K}^{+} \mathrm{NS}$ nanoparticle matrix another potassium independent reference dye that absorbs at a higher wavelength (i.e., NIR-797) so as to acquire NIR absorbing K ${ }^{+}$NS. Generally, NIR wavelengths are preferred for light sources used for in vivo studies, as this minimizes both potential autofluorescence and the ubiquitous Raleigh light scattering, thereby allowing deeper penetration into biological tissues. Having primary amine groups on the surface of the $\mathrm{K}^{+}$NS provides much flexibility for modifications of the sensor. We conjugated an NIR absorbing dye that is insensitive to $\mathrm{K}^{+}$(NIR-797) onto the surface of the $\mathrm{K}^{+} \mathrm{NS}$ (giving NIR-K ${ }^{+}$NS, Figure 5a). Figure $5 b$ shows the absorption spectra of the NIR-K ${ }^{+} \mathrm{NS}$ at different $\mathrm{K}^{+}$concentrations. As shown, the NIR absorbance at $800 \mathrm{~nm}$ can be used as the reference absorbance while that at $660 \mathrm{~nm}$ can still be used as the sensing peak. Figure $5 \mathrm{c}$ shows a calibration curve, plotting the protonation degree (using $660 \mathrm{~nm}$ for sensing and 800 $\mathrm{nm}$ for reference $)^{3}$ versus $\log \left[\mathrm{K}^{+}\right]$. The absorbance-based characterization shows no significant difference in the dynamic sensing range of this modified sensor, compared to the original $\mathrm{K}^{+} \mathrm{NS}$.

Interestingly, the fluorescence of the NIR-K ${ }^{+} \mathrm{NS}$ has quite a significantly different sensing range than the absorbance (Figure 5d,e). The fluorescence of the NIR-K ${ }^{+}$NS gives the most drastic changes from $20 \mathrm{mM}$ to $1 \mathrm{M}$ potassium (Figure 5e). This sensing range suites the intracellular potassium monitoring (typical intracellular potassium concentration is about $150 \mathrm{mM},{ }^{37}$ while that of the sodium concentration is about $10 \mathrm{mM}^{12}$ ). When the majority of the absorbance of $\mathrm{K}^{+} \mathrm{NS}$ is at $660 \mathrm{~nm}$ (i.e., low $\left[\mathrm{K}^{+}\right]$), the fluorescence at $660 \mathrm{~nm}$ is low. When the majority of the absorbance of $\mathrm{K}^{+} \mathrm{NS}$ is at $540 \mathrm{~nm}$ (i.e., high $\left[\mathrm{K}^{+}\right]$), the fluorescence at $660 \mathrm{~nm}$ is significantly higher. The chromoionophore, which is essentially a $\mathrm{pH}$ indicator, stays mostly protonated in the absence of potassium and becomes deprotonated in the presence of potassium. In the fluorescence calibration, the degree of protonation is only dictated by the deprotonated sensing peak ( $540 \mathrm{~nm}$ excitation), thus, forming an opposite trend from that of the absorbance calibration. 


\section{Fluorescence Imaging of $\mathrm{K}^{+} \mathrm{NS}$}

Another potential application of the primary amine groups for the $\mathrm{K}^{+} \mathrm{NS}$ is surface modification with targeting moieties, such as tumor homing F3 peptide ${ }^{34,35}$ and cardiac myoctye homing Cardiac Targeting Peptide (CTP) ${ }^{36}$ Previous in vivo studies indicate that F3 peptide modified nanoparticles show an increased retention time and target tumors significantly better than nontargeted nanopraticles. ${ }^{34,35}$ The $\mathrm{K}^{+} \mathrm{NS}$ was surface modified with F3 peptide and fluorescence images were taken to monitor the uptake of the nanosensor by the cancer cells. Figure 6 shows the fluorescence images of the cancer cells incubated with different types of the nanosensors. Figure 6 a was incubated with $\mathrm{K}^{+} \mathrm{NS}$ without primary amine groups, Figure $6 \mathrm{~b}$ was incubated with $\mathrm{K}^{+} \mathrm{NS}$ containing primary amine groups, and Figure $6 \mathrm{c}$ was incubated with $\mathrm{F} 3$ peptide modified $\mathrm{K}^{+} \mathrm{NS}\left(\mathrm{F} 3-\mathrm{K}^{+} \mathrm{NS}\right)$.

The surfaces of the $\mathrm{K}^{+} \mathrm{NS}$ without primary amine groups are essentially PEGylated surfaces, making it least favorable for the uptake by the cancer cells (Figure 6a). On the other hand, the surface of the $\mathrm{K}^{+} \mathrm{NS}$ containing primary amine groups are positively charged and can be attracted by the negatively charged cellular membrane, leading to the highest uptake by the cancer cells (Figure 6b). During the surface modification with F3 peptide, the $\mathrm{K}^{+} \mathrm{NS}$ is further PEGylated; thus, the surface charge is slightly neutralized compared to the unmodified $\mathrm{K}^{+} \mathrm{NS}$ (Figure 6c). Cellular uptake of the $\mathrm{K}^{+} \mathrm{NS}$ suggests that intracellular potassium imaging can indeed be accomplished through fluorescence imaging.

\section{CONCLUSION}

We report, for the first time to the best of our knowledge, an ion-selective nanosensor enabled through PA imaging. Furthermore, this sensor is bimodal, enabling also fluorescence-based ion-selective imaging. The sensor's sensitivity and selectivity to potassium, as demonstrated by the studies on phantoms, using both traditional absorbance spectroscopy and PA measurements, are well suited for the biologically relevant extracellular $\mathrm{K}^{+}$concentration range $(1-100 \mathrm{mM})$. We also proposed, and demonstrated, a method of conjugating NIR dye molecules to the nanosensors, one that utilizes their surface modification by primary amine groups, thus, allowing having a fluorescence $\mathrm{K}^{+}$sensor with a biologically relevant intracellular potassium concentration sensing range, from $20 \mathrm{mM}$ to 1 M. Also, the NIR absorption can shift the working wavelengths of the nanosensors into the NIR range, thereby facilitating both a lower background noise and a better imaging depth, which would be crucial for in vivo imaging. These results provide a proof of concept for enabling a nanoparticle that serves as a PA ion-selective sensor, and also serves as a fluorescence based, ion-selective sensor. We also demonstrated the ease of attaching a tumor homing ligand to the NS, without affecting its functionality. This work is an important stepping stone and may have a large impact on future studies of the local potassium ion concentrations in the tumor microenvironment in vivo (extracellular through PA imaging and intracellular through fluorescence imaging), especially when considering the importance of investigating the local hyperkalemia found in tumor microenvironments and its reported suppression of immunotherapy. Furthermore, this design for a ISPAO can be easily generalized to most biologically relevant ions, in analogy to traditional ISOs, as well as ISEs. 


\section{Supplementary Material}

Refer to Web version on PubMed Central for supplementary material.

\section{Acknowledgments}

We acknowledge support by NIH/NCI Grant R01CA186769 (R.K., X.W.).

\section{References}

1. Bakker E, Bühlmann P, Pretsch E. Chem Rev. 1997; 97:3083-3132. [PubMed: 11851486]

2. Bühlmann P, Pretsch E, Bakker E. Chem Rev. 1998; 98:1593-1688. [PubMed: 11848943]

3. Mistlberger G, Crespo GA, Bakker E. Annu Rev Anal Chem. 2014; 7:483-512.

4. Xie X, Bakker E. Anal Bioanal Chem. 2015; 407:3899-3910. [PubMed: 25604213]

5. Tan W, Shi Z, Smith S, Birnbaum D, Kopelman R. Science. 1992; 258:778-781. [PubMed: 1439785]

6. Shortreed MR, Dourado S, Kopelman R. Sens Actuators, B. 1997; 38:8-12.

7. Clark HA, Hoyer M, Philbert MA, Kopelman R. Anal Chem. 1999; 71:4831-4836. [PubMed: 10565274]

8. Sumner JP, Aylott JW, Monson E, Kopelman R. Analyst. 2002; 127:11-16. [PubMed: 11827375]

9. Xu H, Aylott JW, Kopelman R. Analyst. 2002; 127:1471-1477. [PubMed: 12475037]

10. Retter R, Peper S, Bell M, Tsagkatakis I, Bakker E. Anal Chem. 2002; 74:5420-5425. [PubMed: 12403602]

11. Brasuel MG, Miller TJ, Kopelman R, Philbert MA. Analyst. 2003; 128:1262-1267. [PubMed: 14667163]

12. Park EJ, Brasuel M, Behrend C, Philbert MA, Kopelman R. Anal Chem. 2003; 75:3784-3791. [PubMed: 14572044]

13. Sumner JP, Kopelman R. Analyst. 2005; 130:528-533. [PubMed: 15776163]

14. Dubach JM, Harjes DI, Clark HA. J Am Chem Soc. 2007; 129:8418-8419. [PubMed: 17567136]

15. Dubach JM, Harjes DI, Clark HA. Nano Lett. 2007; 7:1827-1831. [PubMed: 17497824]

16. Dubach JM, Das S, Rosenzweig A, Clark HA. Proc Natl Acad Sci U S A. 2009; 106:16145-16150. [PubMed: 19805271]

17. Koo Lee YE, Smith R, Kopelman R. Annu Rev Anal Chem. 2009; 2:57-76.

18. Si D, Epstein T, Koo Lee Y-E, Kopelman R. Anal Chem. 2012; 84:978-986. [PubMed: 22122409]

19. Ruckh TT, Mehta AA, Dubach JM, Clark HA. Sci Rep. 2013; 3:3366. [PubMed: 24284431]

20. Xie X, Crespo GA, Zhai J, Szilagyi I, Bakker E. Chem Commun. 2014; 50:4592-4595.

21. Xie X, Zhai J, Bakker E. Anal Chem. 2014; 86:2853-2856. [PubMed: 24579738]

22. Ruckh TT, Skipwith CG, Chang W, Senko AW, Bulovic V, Anikeeva PO, Clark HA. ACS Nano. 2016; 10:4020-4030. [PubMed: 27089024]

23. Xie X, Zhai J, Jarolímová Z, Bakker E. Anal Chem. 2016; 88:3015-3018. [PubMed: 26909875]

24. Brasuel M, Kopelman R, Kasman I, Miller TJ, Philbert MA. Proceedings of IEEE Sensors. 2002; 281:288-292.

25. Barker SLR, Shortreed MR, Kopelman R. Anal Chem. 1997; 69:990-995. [PubMed: 9075401]

26. Shortreed M, Bakker E, Kopelman R. Anal Chem. 1996; 68:2656-2662. [PubMed: 8694263]

27. Cash KJ, Li C, Xia J, Wang LV, Clark HA. ACS Nano. 2015; 9:1692-1698. [PubMed: 25588028]

28. Wang LV, Yao J. Nat Methods. 2016; 13:627-638. [PubMed: 27467726]

29. Xu M, Wang LV. Rev Sci Instrum. 2006; 77:041101.

30. Ray A, Rajian JR, Lee Y-EK, Wang X, Kopelman R. J Biomed Opt. 2012; 17:057004. [PubMed: 22612143]

31. Ray A, Yoon HK, Koo Lee YE, Kopelman R, Wang X. Analyst. 2013; 138:3126-3130. [PubMed: 23598348] 
32. Chen Q, Liu X, Chen J, Zeng J, Cheng Z, Liu Z. Adv Mater. 2015; 27:6820-6827. [PubMed: 26418312]

33. Eil R, Vodnala SK, Clever D, Klebanoff CA, Sukumar M, Pan JH, Palmer DC, Gros A, Yamamoto TN, Patel SJ, Guittard GC, Yu Z, Carbonaro V, Okkenhaug K, Schrump DS, Linehan WM, Roychoudhuri R, Restifo NP. Nature. 2016; 537:539-543. [PubMed: 27626381]

34. Nie G, Hah HJ, Kim G, Lee Y-EK, Qin M, Ratani TS, Fotiadis P, Miller A, Kochi A, Gao D, Chen T, Orringer DA, Sagher O, Philbert MA, Kopelman R. Small. 2012; 8:884-891. [PubMed: 22232034]

35. Reddy GR, Bhojani MS, McConville P, Moody J, Moffat BA, Hall DE, Kim G, Koo Y-EL, Woolliscroft MJ, Sugai JV, Johnson TD, Philbert MA, Kopelman R, Rehemtulla A, Ross BD. Clin Cancer Res. 2006; 12:6677. [PubMed: 17121886]

36. Avula UMR, Yoon HK, Lee CH, Kaur K, Ramirez RJ, Takemoto Y, Ennis SR, Morady F, Herron T, Berenfeld O, Kopelman R, Kalifa J. Sci Transl Med. 2015; 7:311ra172.

37. Walker, HK., Hall, WD., Hurst, JW. Clinical Methods: The History, Physical, and Laboratory Examinations. Butterworths; Boston: 1990.

38. Lu H-F, Lim WS, Wang J, Tang Z-Q, Zhang P-C, Leong KW, Chia SM, Yu H, Mao H-Q. Biomaterials. 2003; 24:4893-4903. [PubMed: 14559002]

39. Moe SM. Primary care. 2008; 35:215-vi. [PubMed: 18486714] 
(a)
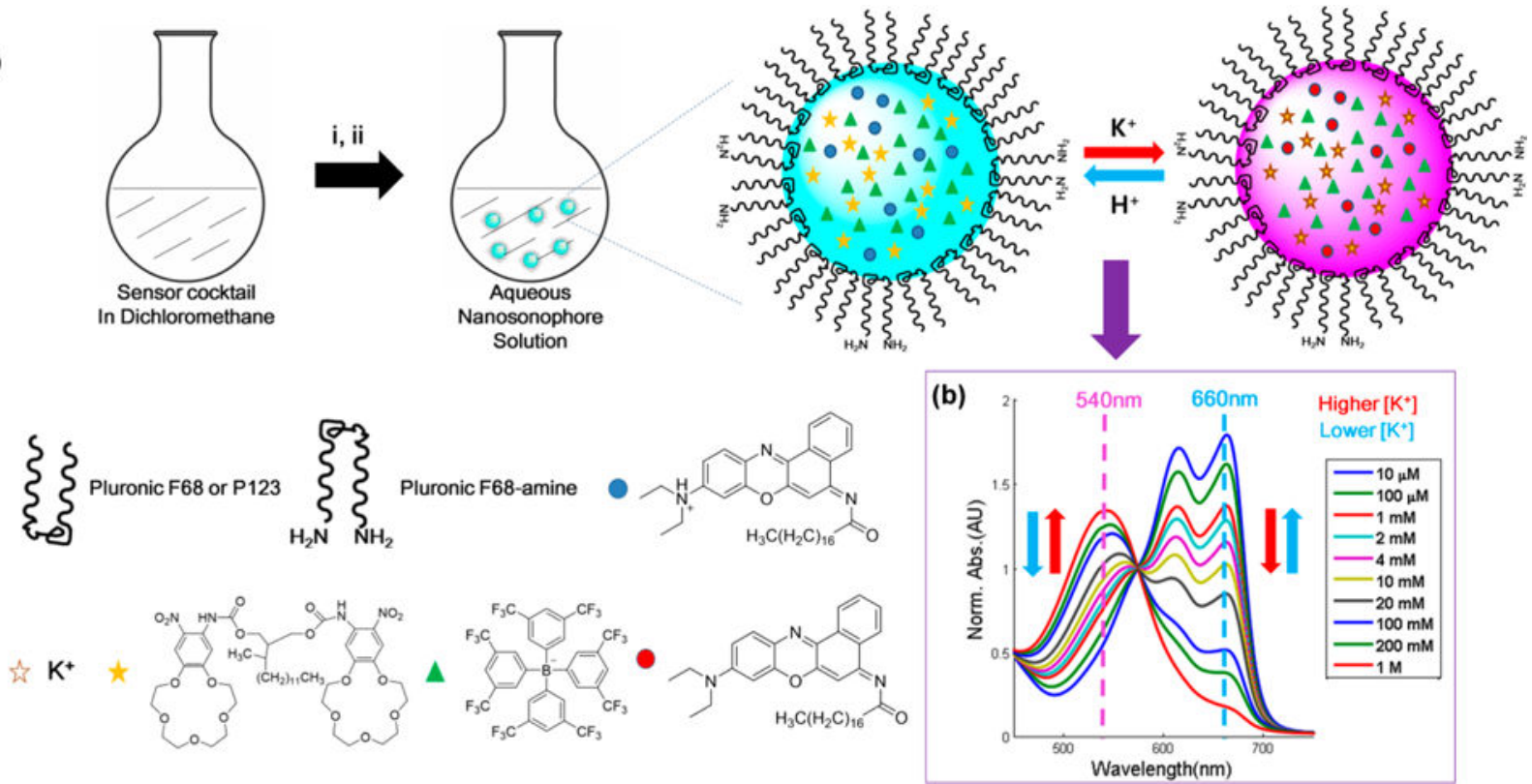

Figure 1.

Nanosensor preparation and sensing schematic. (a) The $\mathrm{K}^{+} \mathrm{NS}$ is prepared in two steps. (i) DCM evaporation via vacuum and rehydration. (ii) Free radical polymerization. The nanosensor matrix contains DOS and poly(butyl methacrylate) (depicted as background). (b) Absorption spectra of $\mathrm{K}^{+} \mathrm{NS}$ at different concentrations of potassium (from $10 \mu \mathrm{M}$ to $1 \mathrm{M}$ ). At low $\left[\mathrm{K}^{+}\right]$, the absorbance at $660 \mathrm{~nm}$ (depicted as blue dashed line in each spectrum) is much higher than the absorbance at $540 \mathrm{~nm}$ (depicted as pink dashed line in each spectrum). At high $\left[\mathrm{K}^{+}\right]$, the absorbance at $660 \mathrm{~nm}$ is much lower than the absorbance at $540 \mathrm{~nm}$. 
(a)

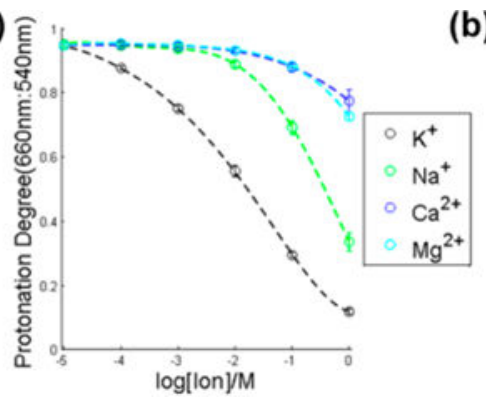

(b)

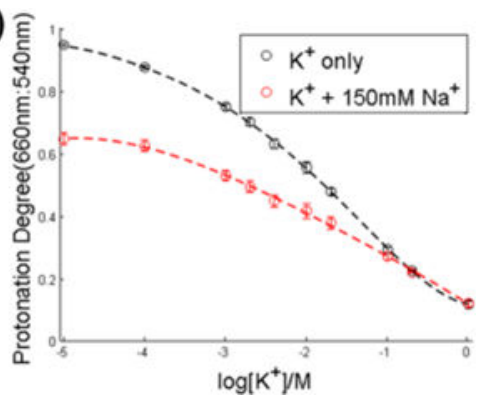

Figure 2.

Characterization of the $\mathrm{K}^{+} \mathrm{NS}$ using UV-vis spectroscopy. (a) Calibration curve of $\mathrm{K}^{+} \mathrm{NS}$ with protonation degree and $\log$ of potassium concentration by using the peak intensity ratios of the $540 \mathrm{~nm}$ absorbance and $660 \mathrm{~nm}$ absorbance of the $\mathrm{K}^{+} \mathrm{NS}$ in a pH 7.4 Trisbuffer $(10 \mathrm{mM}){ }^{3}$ The selectivity of the $\mathrm{K}+\mathrm{NS}$ in comparison to other biological relevant cations $\left(\mathrm{K}^{+}, \mathrm{Na}^{+}, \mathrm{Ca}^{2+}\right.$, and $\mathrm{Mg}^{2+}$ ). (b) Sensitivity of the $\mathrm{K}^{+} \mathrm{NS}$ to $\mathrm{K}^{+}$with and without $\mathrm{Na}^{+}$ background $(150 \mathrm{mM})$. 
(a)

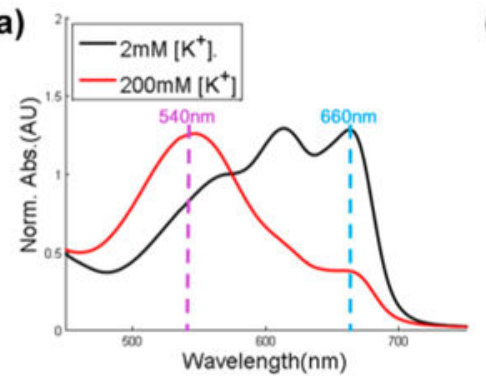

(c)

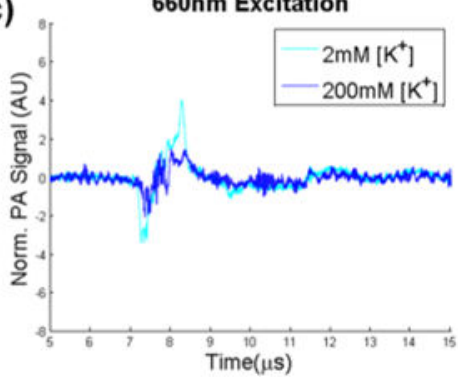

(b)

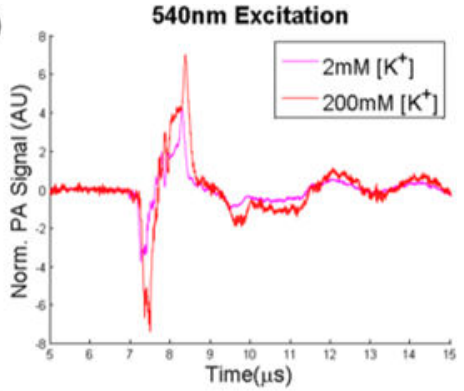

(d)

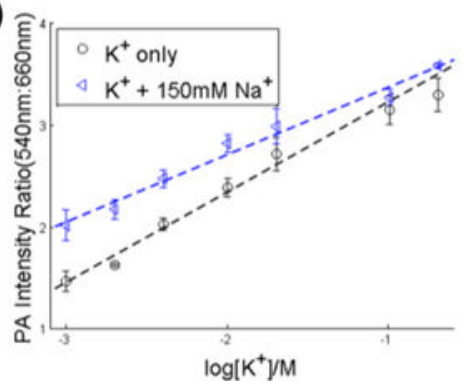

Figure 3.

Characterization of the $\mathrm{K}^{+} \mathrm{NS}$ using PA spectroscopy. (a) Exemplary absorption spectra of $\mathrm{K}^{+} \mathrm{NS}$ at $2 \mathrm{mM}\left[\mathrm{K}^{+}\right]$(black) and $200 \mathrm{mM}\left[\mathrm{K}^{+}\right]$(red). Two sensing peaks are indicated as dashed lines (540 $\mathrm{nm}$ as pink and $660 \mathrm{~nm}$ as blue). (b) Exemplary PA signals of the $\mathrm{K}^{+} \mathrm{NS}$ with $540 \mathrm{~nm}$ excitation. Purple line is PA signal of $\mathrm{K}^{+} \mathrm{NS}$ at $2 \mathrm{mM}\left[\mathrm{K}^{+}\right]$with $540 \mathrm{~nm}$ excitation. Red line is PA signal of $\mathrm{K}^{+} \mathrm{NS}$ at $200 \mathrm{mM}\left[\mathrm{K}^{+}\right]$with $540 \mathrm{~nm}$ excitation. (c) Exemplary PA signals of the $\mathrm{K}^{+} \mathrm{NS}$ with $660 \mathrm{~nm}$ excitation. Cyan line is PA signal of $\mathrm{K}^{+}$ $\mathrm{NS}$ at $2 \mathrm{mM}\left[\mathrm{K}^{+}\right]$with $660 \mathrm{~nm}$ excitation. Blue line is PA signal of $\mathrm{K}^{+} \mathrm{NS}$ at $200 \mathrm{mM}\left[\mathrm{K}^{+}\right]$ with a $660 \mathrm{~nm}$ excitation. (d) PA calibration curve of $\mathrm{K}^{+} \mathrm{NS}$ using the ratio (PA signal intensity at $540 \mathrm{~nm}$ divided by the PA signal intensity at $660 \mathrm{~nm}$ ) from $1 \mathrm{mM}$ to $200 \mathrm{mM}$ [K ${ }^{+}$]. The PA ratios show logarithmic relationship with potassium concentrations in the absence (black circle) and presence (blue triangle) of $150 \mathrm{mM}\left[\mathrm{Na}^{+}\right]$. 
(a)
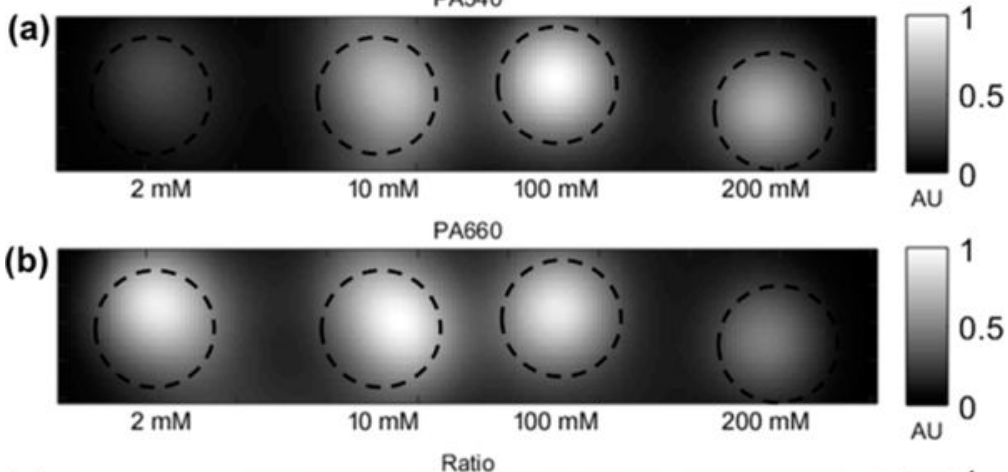

(c)

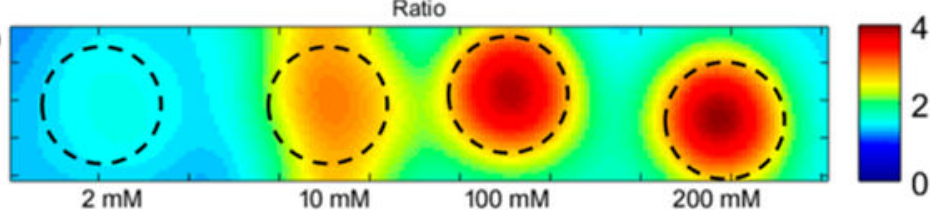

Figure 4.

PA imaging of phantoms containing $\mathrm{K}^{+} \mathrm{NS}$ at different $\left[\mathrm{K}^{+}\right]$, labeled below each image (2, $10,100$, and $200 \mathrm{mM})$. Black dashed circle indicates where the $\mathrm{K}^{+} \mathrm{NS}$ solutions are located in the phantom. The gray scale represents PA signal intensities. (a) PA images of phantoms with $540 \mathrm{~nm}$ excitation. (b) PA images of phantoms with $660 \mathrm{~nm}$ excitation. (c) Ratiometric PA images $(540 \mathrm{~nm}$ over $660 \mathrm{~nm}$ ). The color scale represents the ratio between the PA intensities. 
(a)

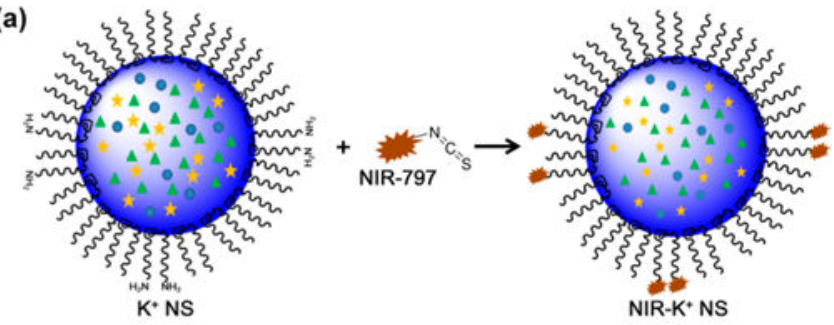

(b)

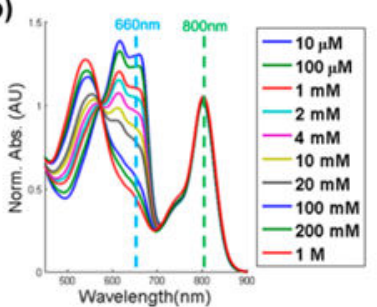

(d)

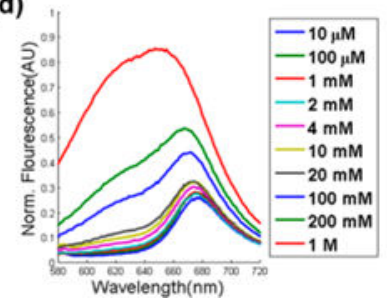

(c)

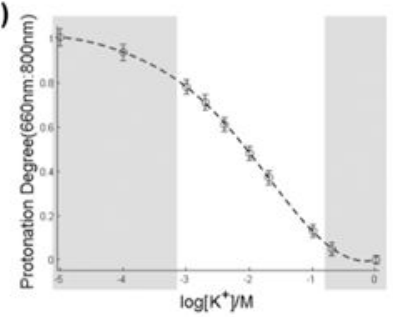

(e)

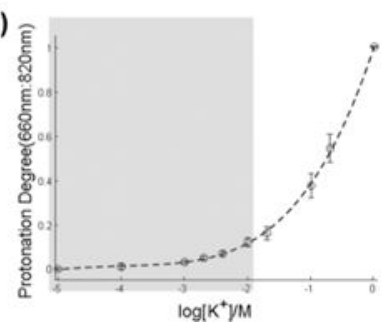

Figure 5.

Optical and sensing properties of NIR-K ${ }^{+}$NS. (a) Schematic of NIR-K ${ }^{+}$NS preparation. (b) Absorption spectra of NIR $\mathrm{K}^{+} \mathrm{NS}$ at different $\mathrm{K}^{+}$concentrations $(10 \mu \mathrm{M}$ to $1 \mathrm{M})$. (c) Calibration curve of $\mathrm{K}^{+} \mathrm{NS}$ with protonation degree vs log potassium concentration, by using the peak intensity ratios of the sensing $660 \mathrm{~nm}$ absorbance and the reference $800 \mathrm{~nm}$ absorbance of the NIR-K ${ }^{+}$NS, in a pH 7.4 Tris-buffer. $^{3}$ (d) Fluorescence emission spectra (540 nm excitation/660 $\mathrm{nm}$ emission) of NIR $\mathrm{K}^{+} \mathrm{NS}$ at different $\mathrm{K}^{+}$concentrations $(10 \mu \mathrm{M}$ to $1 \mathrm{M})$. The spectra were normalized by potassium independent NIR fluorescence (760 nm excitation/820 nm emission, data not shown). (e) Calibration curve of $\mathrm{K}^{+} \mathrm{NS}$ with protonation degree vs log potassium concentration, by using the potassium-dependent sensing emission (620-700 nm emission) and potassium-independent reference emission (800-840 nm emission) of the NIR-K ${ }^{+}$NS, in a pH 7.4 Tris-buffer. $^{3}$ 
(a)

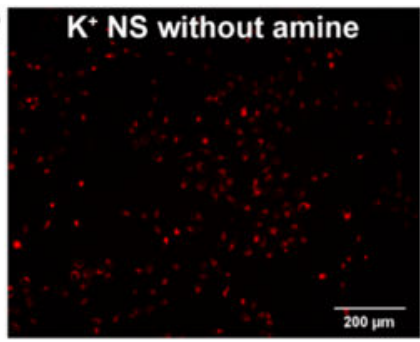

(b)

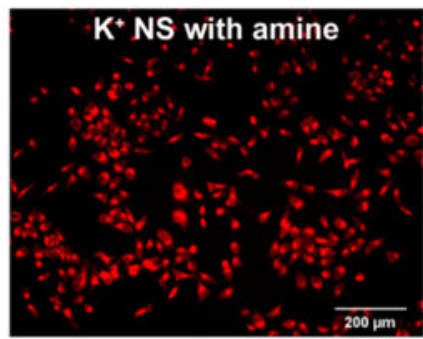

(c)

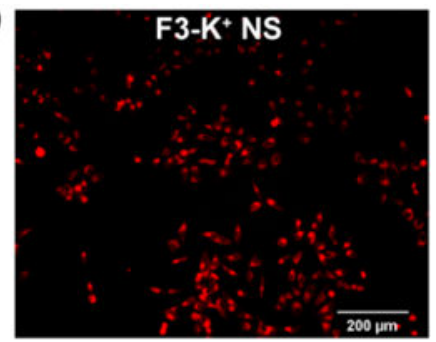

Figure 6.

Fluorescence images of HeLa cells incubated with $\mathrm{K}^{+} \mathrm{NS}(10 \times)$. (a) $\mathrm{K}^{+} \mathrm{NS}$ without primary amine groups. (b) $\mathrm{K}^{+} \mathrm{NS}$ with primary amine groups. (c) F3 peptide modified $\mathrm{K}^{+} \mathrm{NS}$. 